\title{
SHIP RESISTANCE MODELLING in A SMall Model BaSin
}

\author{
Olga Ivanova, Irina Moreva, Irina Blagovidova \& Anna Rodkina
}
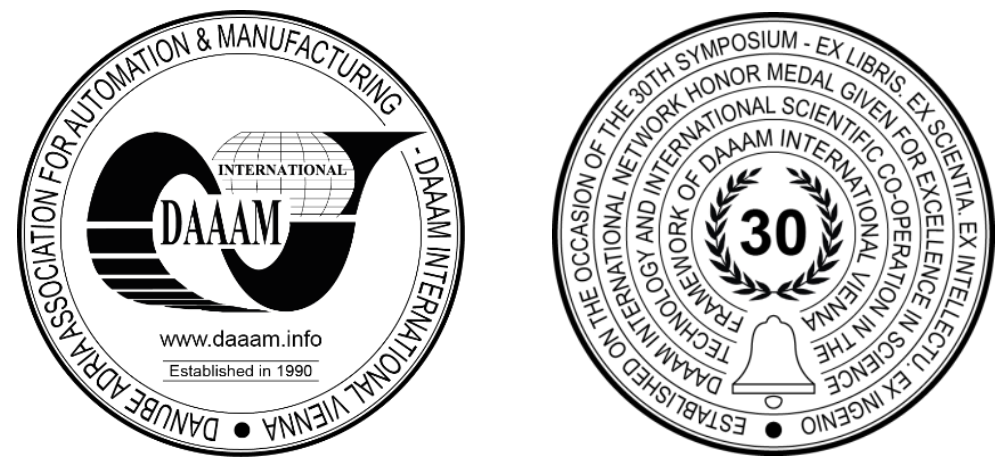

This Publication has to be referred as: Ivanova, O[lga]; Moreva, I[rina]; Blagovidova, I[rina] \& Rodkina, A[nna] (2019). Ship Resistance Modelling in a Small Model Basin, Proceedings of the 30th DAAAM International Symposium, pp.0442-0451, B. Katalinic (Ed.), Published by DAAAM International, ISBN 978-3-902734-22-8, ISSN 1726-9679, Vienna, Austria

DOI: $10.2507 / 30$ th.daaam.proceedings.059

\begin{abstract}
The paper analyzes the effect of a displacement ship hull form, namely bow lines, on the resistance of a displacement ship, based on numerical and model experiments for the purpose of obtaining the hull lines with the least resistance. A 3D model of a dry cargo ship using Tribon M3 computer-aided design system has been developed. The effect of bulbous bow lines on the ship's performance has been assessed and the method for conversing the resistance from a model to a full-scale ship has been proposed based on the results received from the laboratory experiments in a small model basin of Sevastopol State University.
\end{abstract}

Keywords: resistance; bulbous fore end; physical modelling; computer-aided design system; Tribon.

\section{Introduction}

In coping with various design and operating tasks, a need arises to perform a calculation estimation of the ship's propulsion and, consequently, it is necessary to assess the resistance of water to the ship's motion [1].

A preliminary computation of the resistance of motion is one of the most important tasks of the applied ship hydrodynamics. The resistance can be determined reliably enough after developing a lines drawing, fabricating the ship model and testing it in a model basin. This approach is unacceptable at the initial stages of the ship design when it is necessary to expeditiously find the parameters of the ship's propulsion corresponding to the Design Basis. Therefore, the approximate methods for calculating the resistance with the aid of a limited quantity of known parameters and coefficients have been developed.

All up-to-date approximate methods for calculating the resistance are based on the testing of systematic ship model series in model basins. If the hull lines of the ship for which the calculation should be performed are similar to those of the ship models from the tests, such an approximate method can yield sufficiently trustworthy results.

\section{Selection of the method for studying the effect of the displacement ship hull form on the resistance}

Theoretical and experimental studies of the ship resistance are performed to obtain its calculation method and optimize the ship hull lines. While selecting ship hull lines, nowadays a designer relies on a prototype and empirical dependencies. This approach results in the need to carry out multiple costly and time-consuming tests and one is not always confident 
that the optimum ship hull lines have been selected. To select a procedure that would allow a designer to obtain a wavemaking resistance of the ship being designed without carrying out model tests is virtually impossible. When you do not have a prototype or statistical data, even the comparison of different hull forms offers difficulty. For example, the Michell theory represents a classical solution of the problem in a linear form and is often used as the first approximation in developing higher order theories and for optimization of the hull lines. Nevertheless, there remain many questions relating to peculiarities of the Michell integral, the answers to which have not been yet found. Any linear theory usually gives the main part of the problem solution, and for this reason it is very important to figure out the causes of discrepancy between the calculations and the results of the experiments. Modern computational facilities provide us with more opportunities to achieve this.

In the 1960s the scientific researches in the field of wave-making resistance of displacement ships were conducted by admiral and academician Roger Brar. In 1963 he organized an International workshop on theoretical determination of ship wave-making resistance. At the workshop the research trends were outlined to obtain acceptable experimental and computational methods of wave-making resistance determination. An issue on extracting wave-making resistance from the residual resistance was raised first and methods of wave measurement in model basins were considered to precisely determine the wave-making resistance [3].

As it is already known at present, the application of numerical methods, for example for solving wave problems involves many difficulties since it is very difficult to achieve the highest level of accuracy in the calculations performed. The selection of quantity of panels on the hull surface and free surface as well as that of the area needed for calculation is always an independent task. The dependence of the results from a manner of dividing the integration domain significantly influences the final result. If a numerical integration is made, the surface is replaced with either elementary rectangular or a polyhedron at best. In this case, the smoothness of the surface and its first derivative violates. At each point of discontinuity there appears a fictitious system of ship waves that do not exist in real life. Each fictitious system contributes to a wave resistance value. This explains the circumstance that a design value of integrals increases with building up a quantity of partitions. The replacement of the hull with curved panels brings about the smoothness of knuckles among them on the reference hull surface. To achieve the necessary accuracy in numerical modelling for the resistance calculation, we need to have an absolute smoothness of the subintegral surface according to which the integration is made [2], [4].

Moreover, there are no accurate analytical solutions that can be served as a reference. Many researchers verify their numerical methods by comparing them with experimental data. To what extent will this comparison be correct? For example, with a view of obtaining a correct solution to the wave resistance problem it is necessary to integrate the NavierStoks equation with point boundary conditions on the ship hull surface and free liquid surface.

In many cases the physical modelling remains the only way of solving the problem. The physical modelling is performed by testing models in model basins and conversing the results from a model to a full-scale ship in compliance with the provisions of similarity and dimensional theories. Such modelling enables to obtain very accurately the solution to the ship resistance assessment problem. However, the practical feasibility of the pairwise equality of similarity criteria for a model and full-scale ship is restricted by the absence of appropriate low-viscous liquids at present. The results of physical modelling are therefore unfree of scale effect. This circumstance results in an application practice when the crucial tests are performed using large-scale models in large model basins that are highly expensive facilities.

For research purposes and searching activities as well as in educational process the small model basins are used where only small-size models can be tested. To ensure the validity of the modelling results it is necessary to provide the confinement of the scale effect within tolerable limits.

In the second half of the $20^{\text {th }}$ century the idea arose to create ship hull lines not only on the basis of empirical knowledge of ship builders and theoretical developments of scientists in the field of hydrodynamics but also by using the results of dynamic process modelling on large-scale copies. By that time, the necessity had emerged to correct insufficiently accurate design methods of water resistance to ship motion. Altogether, there appeared model basins in which towing tests of large-scale models of ships were being performed by measuring the hull resistance with a dynamometer at various motion velocity.

First (in 1871) was built a model basin of William Froude near Torquay, being $85 \mathrm{~m}$ long, $14 \mathrm{~m}$ broad and $3 \mathrm{~m}$ deep. The first experiments were conducted by Froude on large-scale models of gunboats Swan (1.1 m long) and Raven (3.66 m long) which were moved with a steam winch and a rope. As a result of these experiments, it was found out that the main components of resistance were friction and inherent wave system of the hull which both possess a different nature.

Later on, hydrodynamic model basins were started to be built in other countries. In Russia the first basin of that kind (122 m long, $6.5 \mathrm{~m}$ wide, $3 \mathrm{~m}$ deep) appeared on New Holland Island in Saint-Petersburg in 1894. As early as in the beginning of the 1890s its construction was initiated by Dmitry I. Mendeleyev who studied the wave environment resistance. Several model basins have been currently in use in Russia. In the Krylov State Research Center alone (SaintPetersburg) the model tests are performed in a deep-water basin consisting of two parts of $600 \mathrm{~m}$ and $670 \mathrm{~m}$ in length as well as in an ice, a rotating-arm and a shallow-water basins. There are model basins at Admiral Makarov State University of Maritime and Inland Shipping in Saint-Petersburg (formerly Saint-Petersburg State University of Waterway Communications), at State University in Komsomolsk-na-Amure.

Model basins served as a catalyst for the rapid development of a shipbuilding theory and practice; similarity criteria have started to be developed; besides the towed ones, self-propelled models have appeared; wave generators and 
modelling sea waves have come into use, the effect of trim difference have been started to study. Despite the fact that the present-day shipbuilding science has significantly advanced and accumulated a huge experience largely enabling to optimize hull lines based on computer technology and using statistics or mathematical modelling of physical processes, model basins have lost nothing of their relevance. The practice is a criterion of the verity and the experiment, in our case a model one, is the most reliable and more often economical way to verify the theory until its industrial implementation.

Therefore, the objective of the study was to assess the effect of the displacement ship hull form, namely bulbous bow lines, on the ship's performance and resistance by using numerical and modelling experiments, including the creation of the procedure for conversing the resistance from a model to a full-scale ship according to the results received during the laboratory experiments in a small model basin of Sevastopol State University.

To achieve the set objective the following tasks have been accomplished:

- In Tribon M3 computer-aided design system a three-dimensional ship model with and without various bulbous bow lines has been built;

- Calculations on ship's performance have been performed and conclusion on the feasibility of using the fore bulb has been made, the selection of type of the fore bulb has been justified;

- A physical model of the fore bulb has been developed and created based on its selected type. A series of experiments has been conducted in a small model basin of Sevastopol State University in order to determine the ship resistance taking into account the fore bulb and without it;

- A procedure for conversing the resistance from a model to a full-scale ship has been developed;

- A correlation of the results received in Tribon M3 with the model tests has been made.

This paper is based on the usage of theoretical and practical methods of calculating the ship's performance, methods of performing model tests and data processing methods.

\section{Analysis of principal factors ensuring ship resistance modelling in a small model basin}

The bulbous bow lines in the fore end of the ship create a supplementary ship wave system that, due to the interference with the principal ship wave system, reduces the general ship wave resistance. The gain in the resistance becomes essential at Froude numbers $\mathrm{Fr}=0.25 \ldots 0.35$, reaching its maximum approximately at $\mathrm{Fr}=0.3$.

The usage of the fore bulbs allows to sharpen the fore end of the ship above the bulb, which, in its turn, enables to decrease the wave resistance while maintaining the same displacement. This assumes importance during ballast passages when a fraction of the wave resistance increases in the general water resistance to the ship motion. Under the ballast and load draft conditions the decrease of the hull form resistance due to the reduction in vortex generation in the fore end also contributes to this.

The effect of the bulbs on the resistance depends on its form and size. The size of a bulb is characterized by its relative surface area at the fore perpendicular $f_{\Omega} / \Omega$, measured in fractions of the midship-section area, and by its relative length $l_{\sigma}=\frac{L_{\sigma}}{L}$ (counting from the fore perpendicular) measured in fractions of the ship length between perpendiculars. External conditions determining the effect of bulbous bulges are ship velocity and draft (load and ballast).

Assessing the feasibility of using the bulbs of one or another form, one should consider the effect of the bulb on the hull cost. The presence of the bulb also deteriorates the mooring conditions and complicates the design of an anchoring gear. The effect of the bulb form on the forces taken up by the hull in the slamming is of considerable importance. Notwithstanding a number of disadvantages, the usage of bulbous bow lines in a modern transport shipbuilding is increasingly becoming a standard since it allows to reduce the load on a power plant and save up to $25 \%$ of fuel [5], [6].

\subsection{Effect of the fore bulb form on the ship resistance}

Forms of the bulbous bulges vary greatly. Their main varieties are shown in Figure 1.
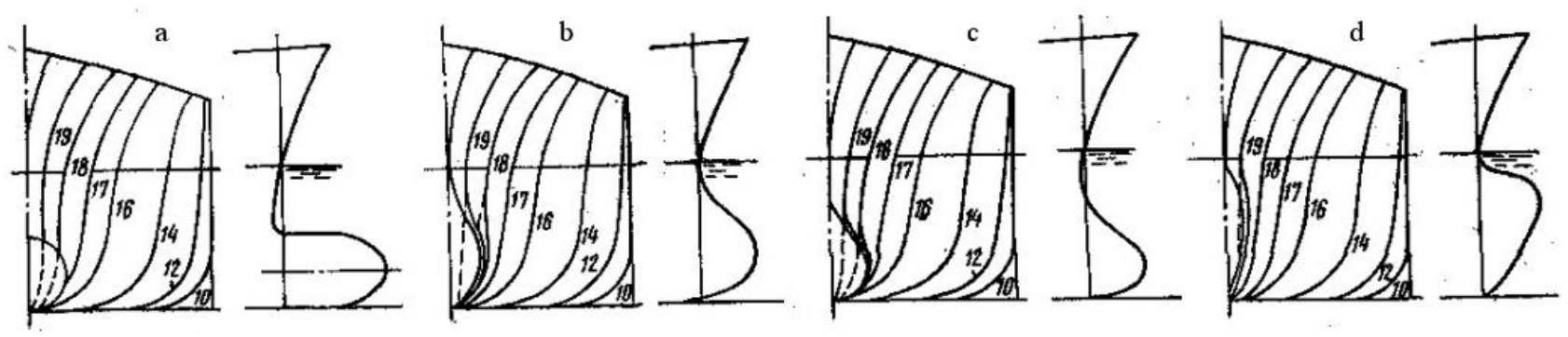

Fig. 1. Fore bulb types

A ram bulb (Fig. 1. a) features a transversal section in the form of a circle. In the fore direction from perpendicular a cylindrical part of the bulb is limited by either a spherical surface or ellipsoidal surface more elongated in a longitudinal direction. In the extreme case a length of the cylinder can be equal to zero. In the fore direction from perpendicular while going to the main hull a diameter of transversal sections is either kept constant or gradually decreases (the cylindrical 
surface is replaced by a conical one). The transversal bulb sections are mated with frames either without transient roundings or with minimum roundings. A tear-drop bulb (Fig. 1. b) is characterized by transversal sections mating smoothly with frames. A pear-shaped bulb (Fig. 1. c) is distinguished from the tear-drop one by a less hull rising and a lower position of the extreme point at the centerline plane section. An SV bulb (Fig. 1. d) has a wedge-shaped transversal section and a cutaway bow edge.

The results of the tests of models of single-screw high-speed transport ships with and without a fore bulb of various sizes and forms performed by G. Haenel and K. Labes in a model basin are known. The main model relates to a ship with the following dimensions: $\mathrm{L}=165 \mathrm{~m} ; \mathrm{B}=23.6 \mathrm{~m} ; \mathrm{T}=9.34 \mathrm{~m} ; \mathrm{V}=20000 \mathrm{~m}^{3} ; \delta=0.55$. The tests covered a range of velocities corresponding to the ship velocity $\mathrm{V}=18 \ldots 26 \mathrm{kN}$ and were performed at various drafts.

Providing a ship draft to the design waterline and motion velocity of more than $20 \mathrm{kN}(\mathrm{Fr}>0,26)$ and using bulbous bow lines instead of the conventional ones, they managed to reduce the output of the power plant by $5-10 \%$ or to increase the velocity by $0.4-0.7 \mathrm{kN}$. However, at the ballast draft the motion velocity decreased by $1-2 \mathrm{kN}$.

At the draft to the design waterline the gain in the resistance was building up as the bulb relative area increased but meanwhile the ship's performances in terms of ballast passages were worsening. In those cases when the relative bulb area remained constant, the change in the bulb form produced a comparatively small effect on the fully-laden ship. The same was a behavior of the SV bulb which, in contrast to other bulbs, was hardly increasing the resistance during the ballast passages. For the ram bulbs, an elongated ellipsoidal head appeared to be more advantageous than a spherical one. The reduction of the ram bulb towards the aft from the fore perpendicular gave insignificant gain in the ballast passages at high motion velocities. In the rest of the cases the bulb reduction was accompanied by an increase in the resistance. The bulb length exerted a minor effect on its efficiency. At the draft to the design waterline an optimal bulb length was changing depending on its form and was not overreaching the limits $l_{\sigma}=2.5 \ldots 5 \%$ most of the time. At the ballast draft the bulb elongation resulted in the resistance increase. Thus, the studies of the effect of the fore bulb forms on the resistance are of experimental nature and associated with a number of difficulties, however, the obtained data enable to improve characteristics of transport ships and save resources.

\subsection{Main ship resistance components in motion}

While studying the water resistance to the ship motion, a working hypothesis on the independence of individual components of the total hydrodynamic resistance has been used. Owing to that hypothesis the process of study of the resistance to the ship motion simplifies significantly since each separate resistance component depends on more limited quality of causes in comparison with the total resistance.

It is proved that the more perfect the division of the resistance into constituent parts the less causes precondition the appearance of one or another part of the total resistance. This lead to the possibility of determining it either by analytical or by experimental methods.

The hydrodynamic principle of resolution the water resistance to the ship motion into separate components is associated with the resolution of surface hydrodynamic forces into tangential and normal components.

The total water resistance to the ship motion can be represented as a sum of three resistances:

$$
R_{x}=R_{T}+R_{V}+R_{W}
$$

where $R_{T}, R_{V}$ and $R_{W}$ - the friction resistance, form resistance and wave-making resistance, respectively.

A simple relation between velocity and resistance cannot reflect a true nature of change of the resistance as a function of the velocity at different modes of relative high velocity and different characteristics of ship forms. To quantify the effect of the relative high velocity on the resistance change, there serve criteria of dynamic similarity of liquid flows enabling to correlate hydrodynamic characteristics of bodies and flows regardless of their actual sizes, velocities and liquid physical properties.

While studying the water resistance to the motion of the sea-going ship model, two criteria of dynamic similarity of liquid flows - the Froude number (wave component) reflecting the similarity of gravity forces in the liquid flows

$$
F_{r}=\frac{v}{\sqrt{g \cdot L}}
$$

and the Reynolds number (viscous component) reflecting the similarity of viscous forces in liquid flows.

$$
R_{E}=\frac{v \cdot L}{V}
$$

It is not possible to simultaneously comply with both those similarity criteria under usual conditions [8]. In the formulas (2) and (3):

$v$ - the model motion velocity relative to the water, $\mathrm{m} / \mathrm{s}$;

$L-$ the design length of the model hull, m;

$g=9.81$ - the gravity acceleration (free-fall acceleration) $\mathrm{m} / \mathrm{s}^{2}$;

$V$ - the kinematic viscosity coefficient, $\mathrm{m}^{2} / \mathrm{s}$. 
The similarity theory of hydromechanical phenomena gives a general solution of the problem on the resistance to the motion of bodies near a viscous liquid surface in the form of a formula of the square resistance law according to which the resistance force is proportional to the liquid density, the velocity of relative motion and the squared linear size of the body which is inherent to the streamlining. A proportionality coefficient in the formula of the square resistance law is a function of hydrodynamic similarity criteria of viscosity forces and liquid weight forces [7], [9], [10].

Assuming a particular linear size in the form of a square root of a value of the model wetted surface, the formula for determining the water resistance to the model steady motion can be represented as:

$$
R=0.5 \cdot C_{T} \cdot \rho \cdot \Omega \cdot v^{2}
$$

where $C_{T}=f \cdot\left(F_{r}, R_{e}\right)$ - the water resistance dimensionless coefficient; $\rho$ - the water density, $\mathrm{kg} / \mathrm{m}^{3} ; \Omega$ - the ship wetted surface area, $\mathrm{m}^{2} ; 0.5$ - is entered into the resistance formula to separate out from it the water head velocity equal to a half of the product $\rho \cdot v^{2}$.

\section{3D ship model building in Tribon M3 computer-aided design system}

In order to achieve the set task it is necessary to build up 3D models of the ship with and without bulbous bow lines. For this purpose, Tribon M3 computer-aided design system has been used which allowed not only to produce a lines drawing but also to select the best form of a bulb depending on ship propulsion characteristics [12].

In the Project Tools module a design of the dry cargo ship was created where the initial date were entered.

In the Form module a ship surface was first generated without a bulb and then with a teardrop bulb and a bulb with a knuckle. We export it from the Form module to the Surface module to build 3D models and to the Lines module to produce a lines drawing of the ship with and without a bulb. A ship with the tear-drop bulb is shown in Figure 2.

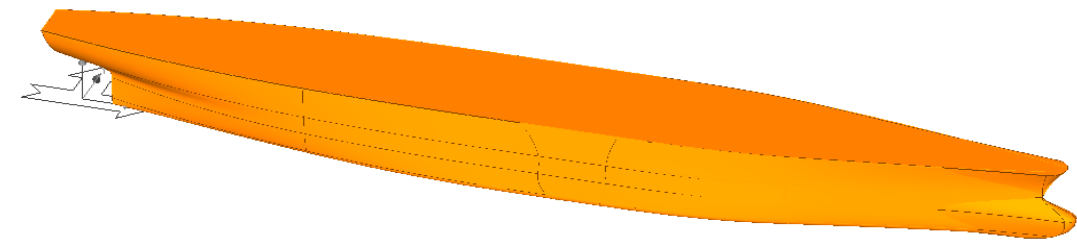

Fig. 2. A dry cargo ship with a tear-drop bulb in the Surface module

\begin{tabular}{|c|l|l|l|}
\hline $\begin{array}{c}\text { Bulb } \\
\text { cross- } \\
\text { sectional } \\
\text { area }\end{array}$ & Pe (kW) & QPC & Pd (kW) \\
\hline \multicolumn{4}{|c|}{ Ship without bulb } \\
\hline no & 1704 & 0.689 & 2473 \\
\hline \multicolumn{4}{|c|}{ Tear-drop bulb. } \\
\hline \multicolumn{4}{|c|}{ Bulb cross-sectional area for 1/2 length } \\
\hline Center of gravity of section = 2.617 m \\
\hline 0 & 1677 & 0.693 & 2419 \\
\hline 7.5 & 1521 & 0.710 & 2143 \\
\hline 8 & 1519 & 0.710 & 2141 \\
\hline 8.5 & 1519 & 0.710 & 2140 \\
\hline 9 & 1519 & 0.710 & 2140 \\
\hline 9.5 & 1521 & 0.710 & 2143 \\
\hline 10 & 1523 & 0.709 & 2147 \\
\hline 11 & 1531 & 0.709 & 2160 \\
\hline 15 & 1600 & 0.701 & 2281 \\
\hline 20 & 1766 & 0.684 & 2580 \\
\hline
\end{tabular}

\begin{tabular}{|c|l|l|l|}
\hline $\begin{array}{c}\text { Bulb } \\
\text { cross- } \\
\text { sectional } \\
\text { area }\end{array}$ & Pe (kW) & QPC & Pd (kW) \\
\hline \multicolumn{4}{|c|}{ Ship with bulb } \\
\hline no & 1704 & 0.689 & 2473 \\
\hline \multicolumn{4}{|c|}{ Bulb with knuckle. } \\
\hline \multicolumn{4}{|c|}{ Bulb cross-sectional area for 1/2 length } \\
\hline 0 & 1683 & 0.693 & 2430 \\
\hline 6.5 & 1540 & 0.708 & 2175 \\
\hline 7.5 & 1538 & 0.708 & 2173 \\
\hline 8.5 & 1542 & 0.708 & 2179 \\
\hline 9 & 1545 & 0.707 & 2185 \\
\hline 9.5 & 1550 & 0.707 & 2194 \\
\hline 10 & 1556 & 0.706 & 2204 \\
\hline 10.5 & 1562 & 0.705 & 2215 \\
\hline 15 & 1669 & 0.694 & 2406 \\
\hline 20 & 1878 & 0.673 & 2791 \\
\hline
\end{tabular}

Table 1. Calculation of output of the ship power plant and propulsion coefficient by changing the bulb area in the Calc/Hydro module

We export the data from the Surface module to the Calc/Hydro module where the output of the power plant and propulsion coefficient for a ship velocity of $15.6 \mathrm{kN}$ are calculated by changing the bulb area. Then we perform an analysis and see that the propulsion coefficient of the dry cargo ship with a bulb is greater than that of the same ship without a bulb. 
While analyzing the data from Table 1 we can conclude that the minimum output of the power plant at the maximum propulsion coefficient is observed in the tear-drop bulb. This leads us to the selection of a fore bulb of tear-drop form for experimental studies.

\section{Bulb model creation}

Having overlapped the lines drawings, a tear-drop bulb in a STL format was cut by using Tribon M3 (Fig. 3, Fig. 4). After exporting it into Autodesk 123D MAKE software, a sketch of the fore bulb was made.

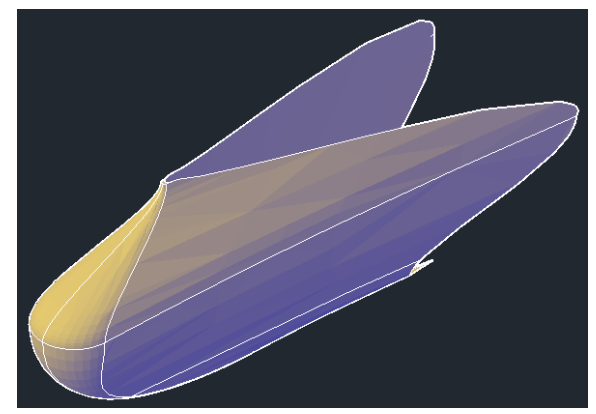

Fig. 3. Bulb 3D-model

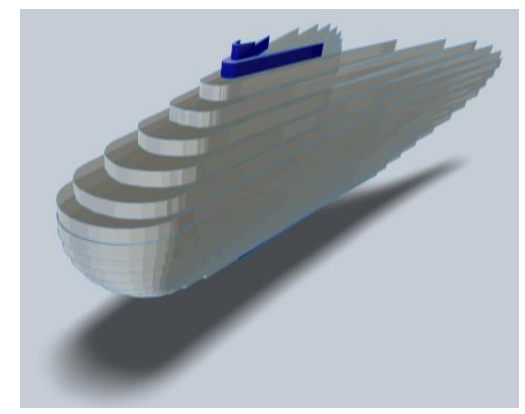

Fig. 4. Bulb divided into constituent parts

A removable bulb for a series 60 dry cargo ship was made of fiberboard, smoothed, primed and painted (Fig. 5, Fig. 6).

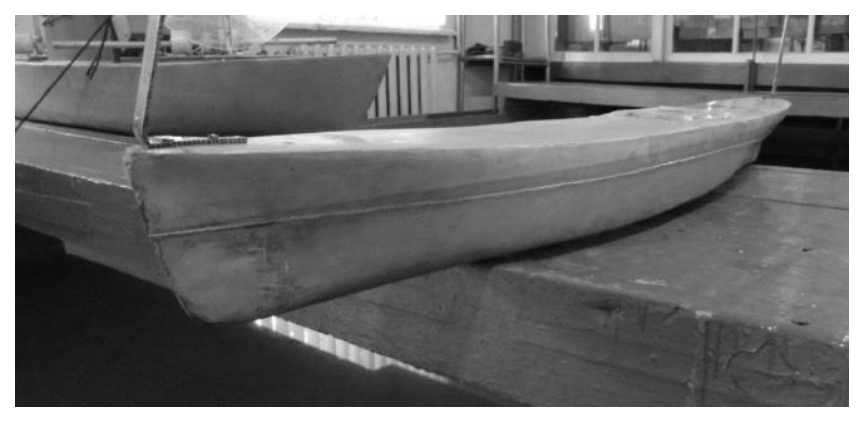

Fig. 5. A series 60 ship model

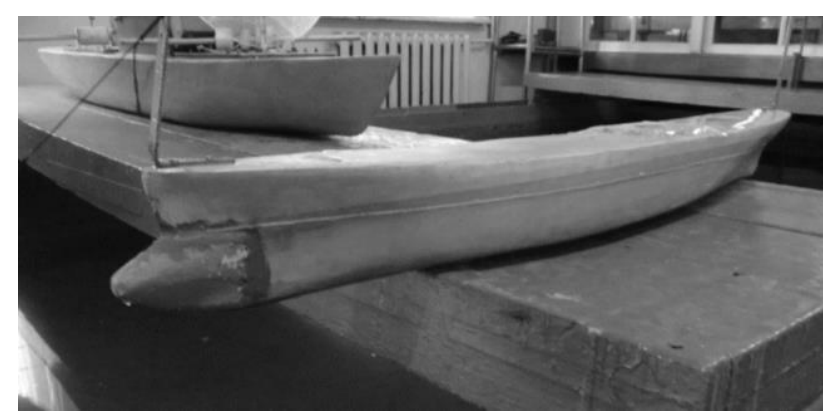

Fig. 6. A series 60 ship model with a bulb

\section{Small model basin of the Sevastopol State University}

There is a gravitation small model basin in the Department "Ocean engineering and shipbuilding" at the Sevastopol State University. The basin hollow part has a length $\mathrm{L}=10 \mathrm{~m}$, a width $\mathrm{B}=3 \mathrm{~m}$ and a water depth of up to $H_{B}=1.5 \mathrm{~m}$. A small length of the basin limited by a wave generator bell and a wave absorber creates a number of problems during ship resistance modelling.

A small water plane length $L_{\mathrm{B}}$ in the basin determines the maximum allowable model length $L_{M}$. Taking into account the accelerating and braking motions of the model in the basin parts (approximately, according to $L_{M}$ ), the streamlining mode establishment part (not less than $L_{M}$ ) and the motion part with a steady velocity (approximately $(3 \ldots 4) L_{M}$ ), it turns out that the basin water plane length shall constitute not less than (6 ...7) $L_{M}$ since the model limiting length shall not exceed $L_{M \max }=\frac{L_{\mathrm{B}}}{(6 \ldots 7)}$, which at the basin water plane length $L_{\mathrm{B}}=8 \mathrm{~m}$ gives $L_{M \max }=1.33 \ldots 1.14 \mathrm{~m}$.

At such lengths for extremely "short-full" ships with a length-breadth ratio $\frac{L}{B}=3 \ldots 4$ the model breadth $B_{M}$ is equal to $0.44 \ldots 0.29 \mathrm{~m}$, which for the basin with a width $B=3$, $\mathrm{M}$ corresponds to a ratio of the basin width to the basin water plane width $\frac{B}{B_{B}}=\frac{1}{6.8} \ldots \frac{1}{10}$ (at the recommended ratios $\frac{B}{B_{B}}=\frac{1}{1.9} \ldots \frac{1}{1.16}$; the model breadth shall be limited by a value of about $\left.B_{M}=0.3 \mathrm{~m}\right)[10]$.

The model basin is equipped with a block for pulling a model, which is a system of rigidly fixed blocks of different diameters. A block for spooling a towing rope has a greater diameter $(314.2 \mathrm{~mm})$. A block for pulling a counterweight load has a less diameter $(74.0 \mathrm{~mm})$, respectively. A schematic diagram of the model pulling block and towing gear forces is shown in Figure 7. 


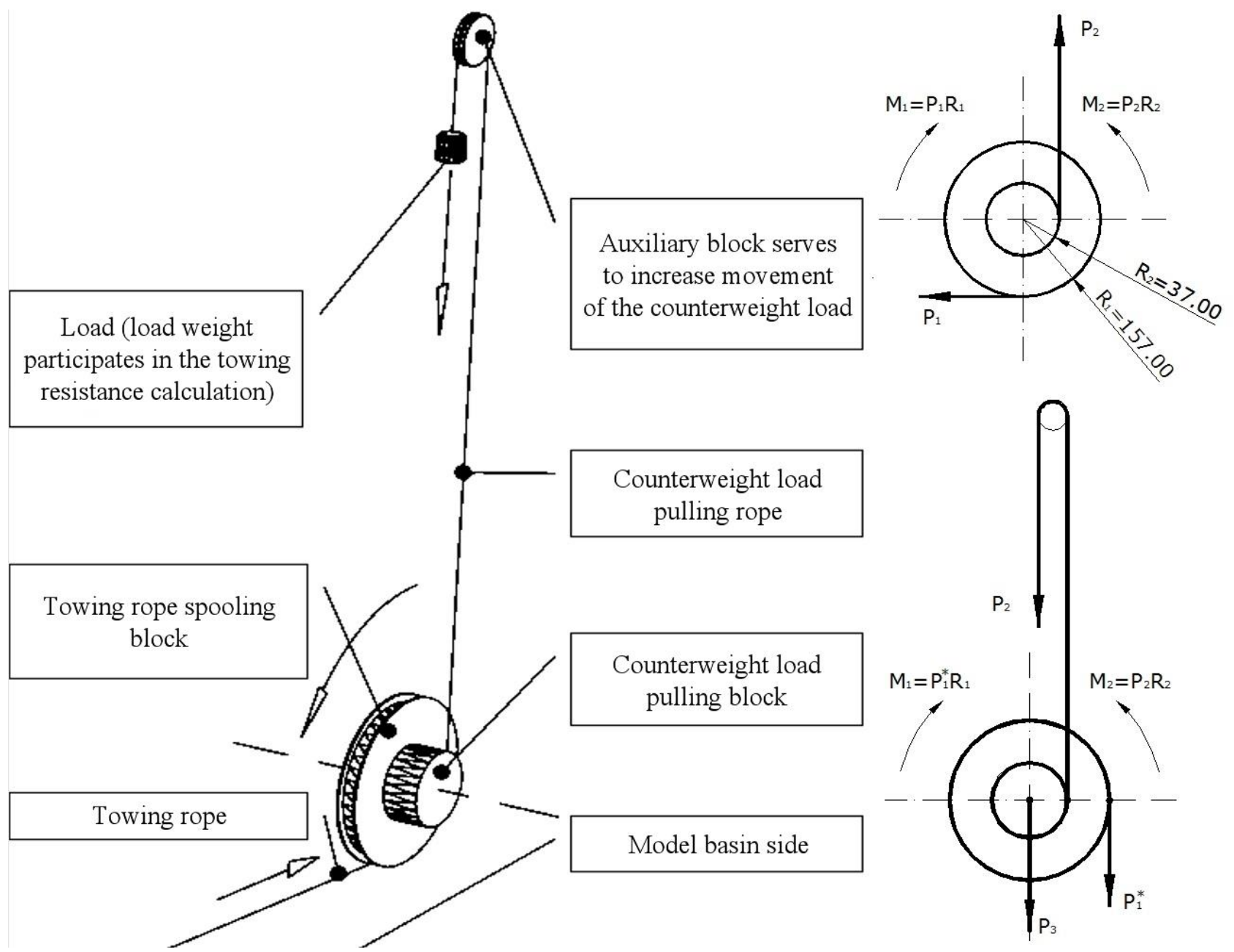

Fig. 7. A schematic diagram of the block for pulling the model and forces arising in the block during the model pulling

The difference of diameters of the towing rope spooling block and counterweight load pulling block is conditioned by an effort to decrease the load movement while maintaining a distance of model towage in the basin hollow part. While the model is being pulled with a constant load, there is produced a difference of forces arising at the force vector application points (Fig. 7).

According to Figure $7, \mathrm{P}_{1}$ determines a towing resistance value. Based on the system equilibrium $(\mathrm{M} 1=\mathrm{M} 2)$, the value $\mathrm{P}_{1}$ is calculated from the following Formula

$$
P_{1}=\frac{P_{2} \cdot R_{2}}{R_{1}} \Rightarrow m_{1}=\frac{m_{2} \cdot R_{2}}{R_{1}}
$$

where $m_{2}-$ the suspended load mass, $\mathrm{kg}$.

During the experiments on determining the water resistance to the model motion the losses from friction in the towing gear were also taken into account. The main part of mechanical losses depending on the load appears in a bearing of the drive shaft [5].

As it follows from the Formula (5), $\mathrm{P}_{1}$ is a towing resistance value. To take into account the losses in the towing gear we need to introduce a correction. According to [11], the towing resistance can be determined from the Formula

$$
P_{R}=\left[\frac{P_{2} \cdot R_{2}}{R_{1}}-\frac{f}{R_{1}}\left(P_{2}+P_{3}\right)\right]=\left[\frac{m_{2} \cdot R_{2}}{R_{1}}-\frac{f}{R_{1}}\left(m_{2}+m_{3}\right)\right] \cdot g
$$

where $m_{3}$ - the mass of the towing gear (system of blocks), $\mathrm{kg} ; f$ - the rolling friction coefficient (bearing reduced load arm), $\mathrm{m} ; f=\frac{m_{2} \cdot R_{2}-m_{1}^{*} \cdot R_{1}}{m_{1}^{*}+m_{2}+m_{3}}-$ the rolling friction coefficient is determined from this formula; $m_{1}^{*}-$ the counterweight load mass, while determining the losses from friction in the towing gear, $\mathrm{kg}$.

The measurement of parameters (covered distance, time, model motion velocity) was made by fixing the position of a block at a certain time of its axial rotation.

The principle of measuring the parameters is based on recording the time between electrical circuit contact closures. The circuit is closed at the moment of passing a magnetic field source near a sealed contact. The magnetic field sources 
(permanent magnets) are installed at equal-spaced angular and linear values relative to a block rotation axis. The parameters are recorded and processed using a computer connected into a circuit of the sealed contact.

The results are recorded and processed using the software specially developed to perform towing tests in a model basin [12].

\section{Processing of results of experimental studies}

The model of a dry cargo ship with and without a bulb was tested with three loads of $200 \mathrm{~g}, 300 \mathrm{~g}$ and $400 \mathrm{~g}$, which corresponds to various velocities of the model motion. The measurements were recorded using a velocity calculation program. The results of the experiments of the model of a ship with and without bulbous bow lines for various velocities are shown in Table 2.

\begin{tabular}{|c|c|c|c|c|c|c|c|}
\hline & \multirow{2}{*}{$\begin{array}{c}\text { Covered } \\
\text { Nostance - S } \\
{[\mathbf{m}]}\end{array}$} & \multicolumn{2}{|c|}{$\begin{array}{c}\text { Model velocity - V, m/s - exponential } \\
\text { regression }\end{array}$} & \multicolumn{3}{|c|}{$\begin{array}{c}\text { Model velocity - V, m/s - exponential } \\
\text { regression }\end{array}$} \\
\cline { 3 - 8 } & & $\mathbf{2 0 0}[\mathbf{g}]$ & $\mathbf{3 0 0}[\mathbf{g}]$ & $\mathbf{4 0 0}[\mathbf{g}]$ & $\mathbf{2 0 0}[\mathbf{g}]$ & $\mathbf{3 0 0}[\mathbf{g}]$ & $\mathbf{4 0 0}[\mathbf{g}]$ \\
\hline 1 & 0.0000 & 0.0000 & 0.0000 & 0.0000 & 0.0000 & 0.0000 & 0.0000 \\
\hline 2 & 0.1645 & 0.0782 & 0.0877 & 0.1081 & 0.0657 & 0.0899 & 0.0972 \\
\hline 3 & 0.3290 & 0.1471 & 0.1664 & 0.2044 & 0.1253 & 0.1705 & 0.1849 \\
\hline 4 & 0.4935 & 0.2078 & 0.2370 & 0.2901 & 0.1793 & 0.2426 & 0.2642 \\
\hline 5 & 0.6581 & 0.2613 & 0.3003 & 0.3663 & 0.2284 & 0.3072 & 0.3357 \\
\hline$\cdots$ & $\cdots$ & $\cdots$ & $\cdots$ & $\cdots$ & $\cdots$ & $\cdots$ & $\cdots$ \\
\hline 38 & 6.0870 & 0.6519 & 0.8375 & 0.9691 & 0.6872 & 0.8458 & 0.9766 \\
\hline 39 & 6.2516 & 0.6527 & 0.8391 & 0.9705 & 0.6890 & 0.8474 & 0.9788 \\
\hline 40 & 6.4161 & 0.6533 & 0.8405 & 0.9718 & 0.6906 & 0.8487 & 0.9807 \\
\hline 41 & 6.5806 & 0.6539 & 0.8418 & 0.9729 & 0.6921 & 0.8499 & 0.9825 \\
\hline 42 & 6.7451 & 0.6544 & 0.8429 & 0.9739 & 0.6934 & 0.8510 & 0.9842 \\
\hline
\end{tabular}

Table 2. A summarized data on the results of the experiment with and without a bulb for various loads

The test results were conversed from the model to the full-scale ship according to the scheme recommended by ITTC-78 [4], which is set out below.

The ship resistance $R$ under conditions of speed trials is determined by the relationship:

$$
R=\frac{C_{T} \cdot \Omega \cdot \rho \cdot V^{2}}{2}, \mathrm{kN}
$$

where $C_{T}$ - the total resistance coefficient of the full-scale ship; $\rho$ - the sea water density, $\mathrm{t} / \mathrm{m}^{3} ; \Omega-$ the ship wetted surface area, $\mathrm{m}^{2} ; \mathrm{V}-$ the design motion velocity, $\mathrm{m} / \mathrm{s}$.

According to "scheme 2"' (scheme of ITTC-78), the ship total resistance coefficient is determined as follows:

$$
C_{T}=(1+k)-C_{F 0}(R e)+C_{W}(F r)+C_{A P}+C_{A A}+d C_{F}
$$

In doing so, $C_{F 0}(R e)$ is taken according to the formula of ITTC-57. $C_{A P}$ [4] - the hull-appendage coefficient during tests of large models is determined based on the results of extrapolation for large $R_{e}$ values of the resistance coefficient of the model fitted with appendages, and the same model without appendages ("bare hull"); the value $C_{A P}$ changes depending on the quantity of propellers and rudders as well as the hull fullness.

While testing small models it is not possible to provide a turbulent flow of miniature appendages, so small models are tested without appendages - as "bare hull" and the hull-appendage coefficient is entered in the calculation in compliance with the recommendations of reference guidelines and industry guidance documents. For example, for a single-screw ship it is taken $C_{A P}=f(L)$.

When using "scheme 2", the air resistance coefficient $C_{A A}$ under the conditions of speed trials. According to ITTC-78, $C_{A A}$ is determined approximately as:

$$
C_{A A}=\frac{F_{T}}{(1000 \cdot \Omega)}
$$

and the correction for roughness of the newly painted shell plating $d C_{F}$ - according to the formula recommended by ITTC-78 


$$
d C_{F}=\left[105 \cdot\left(\frac{R_{M A}}{L}\right)^{\frac{1}{3}}-0.64\right] \cdot 10^{-3}
$$

where the design roughness is taken equal to $R_{M A}=1.50 \cdot 10^{-4} . C_{W}$ is determined from the following formula, based on the results of model testing of the given ship in a model basin

$$
C_{W}(F r)=C_{T}(F r)-C_{f 0}(R e(F r)) \cdot(1+k),
$$

where $k$ - the shape coefficient determined as stated above; $\Omega$ - the wetted surface of the ship "bare hull" $\left(\mathrm{m}^{2}\right)$ is determined according to a ship lines drawing by integrating a "curve of wetted half-perimeters" of frames $\mathrm{I}=f(x)$ with

\begin{tabular}{|c|c|c|c|c|c|c|}
\hline \multirow{3}{*}{$\begin{array}{l}\text { Calculation } \\
\text { components }\end{array}$} & \multicolumn{3}{|c|}{ without bulb } & \multicolumn{3}{|c|}{ with bulb } \\
\hline & \multicolumn{3}{|c|}{$\mathrm{V}, \mathrm{m} / \mathrm{s}$} & \multicolumn{3}{|c|}{$\mathrm{V}, \mathrm{m} / \mathrm{s}$} \\
\hline & 0.65 & 0.65 & 0.83 & 0.68 & 0.84 & 0.97 \\
\hline$V^{2}$ & 0.4225 & 0.4225 & 0.6948 & 0.4665 & 0.7090 & 0.9432 \\
\hline $\mathrm{Fr}$ & 0.2110 & 0.2110 & 0.2706 & 0.2218 & 0.2734 & 0.3153 \\
\hline$\Omega_{M}, \mathrm{~m}^{2}$ & \multicolumn{3}{|c|}{1.6543} & \multicolumn{3}{|c|}{1.7176} \\
\hline $\mathrm{R}_{H}, \mathrm{~N}$ & 0.4621 & 0.4621 & 0.6931 & 0.4621 & 0.6931 & 0.9242 \\
\hline$\frac{\mathrm{C}_{m}}{C_{f 0}}$ & 1.7220 & 1.7220 & 1.6060 & 1.3534 & 1.3383 & 1.3410 \\
\hline $\mathrm{k}$ & 0.7220 & 0.7220 & 0.6060 & 0.3534 & 0.3383 & 0.3410 \\
\hline$\Omega_{H}, \mathrm{~m}^{2}$ & \multicolumn{3}{|c|}{1654.3} & \multicolumn{3}{|c|}{1717.6} \\
\hline $\mathrm{Re}_{H}$ & 383996673.5 & 383996673.5 & 492445631.6 & 403503881.5 & 497457556.3 & 573750709.2 \\
\hline$C_{A P}$ & \multicolumn{3}{|c|}{$0.15 * 10^{-3}$} & \multicolumn{3}{|c|}{$0.15 * 10^{-3}$} \\
\hline$C_{A A}$ & \multicolumn{3}{|c|}{$0.11 * 10^{-3}$} & \multicolumn{3}{|c|}{$0.11 * 10^{-3}$} \\
\hline$d C_{F}$ & \multicolumn{3}{|c|}{$0.64 * 10^{-3}$} & \multicolumn{3}{|c|}{$0.64 * 10^{-3}$} \\
\hline $\mathrm{C}_{f 0}$ & 0.001729969 & 0.001729969 & 0.001674568 & 0.001729969 & 0.001674568 & 0.001643123 \\
\hline$C_{W}$ & \multicolumn{3}{|c|}{$0.1 * 10^{-5}$} & \multicolumn{3}{|c|}{0.00001} \\
\hline$C_{M}$ & 0.0038691 & 0.0038691 & 0.0035794 & 0.003216165 & 0.00312819 & 0.0030918 \\
\hline $\mathrm{V}_{H}, \mathrm{~m} / \mathrm{s}$ & 6.5 & 6.5 & 8.3 & 6.83 & 8.42 & 9.71 \\
\hline $\mathrm{R}, \mathrm{kN}$ & 138.5 & 138.5 & 210.8 & 127.2002089 & 188.029069 & 247.24772 \\
\hline
\end{tabular}
respect to $\mathrm{x}$ as $\Omega=2 \int_{L} l(x) d x$.

Table 3. Conversion of the results from the model to the full-scale ship

Based on the results set out in Table 3, the relationship of the resistance from the velocity was obtained while conversing from the model to the full-scale ship with consideration for a fore end. The correlation between the experimental and design data obtained using Tribon M3 is shown in Table 4.

\begin{tabular}{|l|c|c|c|c|c|c|}
\hline & \multicolumn{3}{|c|}{ without bulb } & \multicolumn{3}{c|}{ with bulb } \\
\hline $\mathrm{V}_{S}, \mathrm{kn}$ & 15 & 15.6 & 16.2 & 15 & 15.6 & 16.2 \\
\hline$V=V_{S} \cdot 0.5144, \mathrm{~m} / \mathrm{s}$ & 7.716 & 8.02 & 8.333 & 7.716 & 8.02 & 8.333 \\
\hline $\mathrm{P}_{E}, \mathrm{~kW}$ & 1439 & 1704 & 2028 & 1309 & 1519 & 1793 \\
\hline$P=\frac{P_{E}}{V}, \mathrm{kN}$ & 186.5 & 212 & 243.4 & 169.6 & 189.18 & 215.161 \\
\hline$P_{\text {exper }}, \mathrm{kN}$ & 170.5 & 200 & 215 & 158 & 180 & 208 \\
\hline
\end{tabular}

Table 4. Correlation of the results

The motion velocity of $15.6 \mathrm{kN}(8.02 \mathrm{~m} / \mathrm{s})$ of the ship without a bulb, which was calculated in Tribon M3, corresponds to the resistance of $212 \mathrm{kN}$, and on the basis of the experimental data the same velocity corresponds to the resistance of $200 \mathrm{kN}$. A relative deviation between the design and experimental resistance values for the ship without a bulb is equal to $5.6 \%$. With a bulb taken into account, the abovementioned velocity corresponds to the resistance equal to $189.2 \mathrm{kN}$, and on the basis of the experimental data the same velocity corresponds to the resistance of $180 \mathrm{kN}$. Hence the relative deviation between the design and experimental resistance values for the ship with a bulb taken into account is $4.76 \%$. 
The values of relative deviations are within the allowable limits of 5-7\%, which is evidence that the results received empirically are trustworthy.

\section{Conclusion}

As a result of the work done, the effect of the fore bulbs on ship's velocity and resistance has been revealed. It has been proved that the effect of the bulbous bow lines depends on the form and sizes of a bulb. To achieve the assigned objective the following tasks have been accomplished: lines drawings of the ship with and without various bulbous bow lines have been produced in Tribon M3; the calculations on the ship's performance have been made and on the basis of them a conclusion on the feasibility of using a fore bulb has been made. Based on the results of the calculations, a tear-drop bulb has been selected; according to the selected type of the bulb, its physical model has been created and a series of experiments has been conducted in a small model basin of Sevastopol State University to determine the resistance of the ship with a bulb taken into account and without it; using the scheme recommended by ITTC-78, a procedure for conversing the resistance from a model to a full-scale ship has been developed; the correlation of the results received by numerical and experimental methods is evidence that the model studies are trustworthy. Based on the results, a tear-drop bulb has been proved to be most feasible for the selected type of the ship. With such a bulb, the propulsion coefficient has the greatest value equal to 0.710 and the output of the power plant is the least $1519 \mathrm{~kW}$.

The results of the work can be used for research purposes and in educational process of shipbuilding higher educational institutions for preliminary calculation of the ship motion resistance and for assessment of the effect of the fore end form on propulsive performance.

The directions for future research lies in the development of a new digital equipment complex and methods for the experimental determination of the ship resistance with various body lines, including projected ones, in small experimental basins. And in conducting a series of experiments with the aim of creating a numerical model for determining the resistance of new designed ship body lines.

\section{References}

[1] Zuyev V.A., Kalynyna N.V., Rabazov Yu.I. Selection of main characteristics of sea-going transport ships at the initial design stage for naval cadets of the Navy Engineering Institute and students of higher educational institutions, Nizhny Novgorod State Technical University named after R.E. Alekseev. Type: study guide. ISBN: 978-5-93272-423-1, Nizhny Novgorod, 2007, pp. 225.

[2] Gotman A.Sh. Regarding the interference of ship bow and aft wave systems. Materials on sharing the experience: Experimental methods for studying the behavior of ships and floating facilities in severe conditions of stormy navigation, Leningrad, 1989. Issue 469. P. 13-49.

[3] Kostyukov A.A. Theory of ship waves and wave resistance, Leningrad, Sudpromgyz Publ., 1959, pp. 310.

[4] Kostyukov A.A. Interaction of bodies moving in liquid, Leningrad, Sudostroyenye Publ., 1972, pp. 312.

[5] Gryschenko G.N., Zyn'kovsky-Gorbatenko V.G. Ship resistance modelling in a small model basin. Bulletin (Vestnik) of Sevastopol Technical University: Collection of scientific papers, Sevastopol, 2005.

[6] Ivanova, O[lga]; Dushko, V[eronika] \& Rodkina, A[nna] (2016). Experimental Researches Automation of Spatial Oscillations of the Floating Ocean Engineering Systems in the Wave Basin, Proceedings of the 26th DAAAM International Symposium, pp.1059-1067, B. Katalinic (Ed.), Published by DAAAM International, ISBN 978-3902734-07-5, ISSN 1726-9679, Vienna, Austria. DOI: 10.2507/26th.daaam.proceedings. 149.

[7] Hydrodynamics of High-Speed Marine Vehicles, ODD M. Faltinsen, Norwegian University of Science and Technology, Cambridge University Press 2005, pp115-120.

[8] Nogyd L.M. Design of sea-going ships, Leningrad, Sudostroyeniye Publ., 1976, pp. 208.

[9] Shallow Water and Supercritical Ships, Lakhovitsky A.G., Backbone publishing Company, 2007.

[10] Dawson C.W. A practical computer method for solving ship-wave problems// Proc. 2-th Int. Conf. Number. Ship Hydrodyn. - Berkeley, 1977. - P. 30-38.

[11] Lekarev G.V., Nesin D.J., Pogodaeva A.S. Influence investigation of the bow bulb cross-section relative area of container ships on the resistance coefficient. Journal of the Sevastopol National Technical University. Issue 147/2014. Series: Mechanics, Power Engineering, Ecology, P. 68-72.

[12] Kramar V. The frequency method of analysis of stability of the multidimensional automatic control system. Annals of DAAAM for 2009 \& Proceedings of the 20th International DAAAM Symposium, Volume 20, Published by DAAAM International, Vienna, Austria, 2009 p-0769-0770. 